\title{
A filosofia no ensino médio à luz da perspectiva socrática da reflexão e do
}

\author{
questionamento 3
}

\author{
Maurilio Gadelha Aires ${ }^{4}$
}

RESUMO: Sócrates pode ser considerado como um dos primeiros filósofos a estabelecer um método de ensino da Filosofia, baseado no questionamento e na problematização, aspectos tão caros a uma postura reflexiva diante da realidade. A Filosofia no modelo socrático, a ser ensinada, pode ser vista como um compromisso de pensar os aspectos da vida cotidiana de maneira crítica, criativa e comprometida. Nesse sentido, o caminho a ser percorrido se pauta no perguntar e no perguntar-se. Sócrates, que havia tomado como norte a máxima de que "[...] a vida sem exame não é vida digna de um ser humano", tinha como caminho a busca do saber através do processo reflexivo. Somente se interrogando e interrogando as coisas e aos outros é que se poderia distanciar-se de meras opiniões sem fundamento seguro, pautadas tão somente numa espécie de comodidade que o pensamento cotidiano mostra por já estar pensado. O presente trabalho pretende lançar um olhar sobre o patrono da Filosofia, sobretudo no que diz respeito a sua inserção na História da Filosofia, como divisor de águas entre o período cosmológico e o antropológico, arguindo em favor dessa mudança como positiva para uma educação reflexiva, tão cara aos dias atuais. Nesse sentido, trata-se muito mais de uma defesa do método reflexivo no ensino de Filosofia, do que propriamente uma apologia de Sócrates. Outrossim, procurar-se-á ressaltar a importância em se construir um ambiente ético que favoreça o debate aberto e sincero acerca das questões que naturalmente surgem ao se colocar em ação o método socrático. Palavras chave: método reflexivo, ensino de Filosofia, diálogo e ética.

\section{The Middle School Philosophy in the light of the Socratic perspective of reflection and questioning}

\begin{abstract}
Socrates can be considered as one of the first philosophers to establish a method of teaching Philosophy, based on the questioning and problematization so dear to a reflexive stance in the face of reality. The Philosophy in the Socratic model, to be taught, can be seen as a commitment to thinking about aspects of everyday life in a critical, creative and committed way. In this sense, the path to be traversed is based on asking and wondering. Socrates, who had taken as his north the maxim that "[...] life without examination is no life worthy of a human being", had as his path the search for knowledge through the reflexive process. Only by questioning himself and questioning things and others could he distance himself from mere opinions without a sound basis, therefore based only on a kind of comfort that everyday thinking shows for having already been thought. The present work intends to throw a glance at the patron of

\footnotetext{
${ }^{3}$ Artigo resultante de trabalho apresentado no XVII encontro do NESEF. Curitiba, UFPR, 22 e 23 de junho de 2017.

${ }^{4}$ Professor de Filosofia do IFRN; mestre em Filosofia (UFRN); doutor em Educação (UFRN). E mail: maurilio.aires@ifrn.edu.br
} 
Philosophy, particularly with regard to his inclusion in the History of Philosophy, as a watershed between the cosmological period and the anthropological period, arguing in favor of this change as positive for a reflexive education, so dear to the present days. In this sense, it is much more a defense of the reflexive method in the teaching of Philosophy than an apology of Socrates. In addition, it aims to highlight the importance in building an ethical environment that encourages an open and honest debate about the issues that naturally arise when the Socratic method is put into action.

Key Words: reflexive method, teaching Philosophy, dialogue and ethics.

Submetido em: julho de 2017. Aprovado em: dezembro de 2017.

\section{Introdução}

Sócrates pode ser considerado como um dos primeiros filósofos a estabelecer um método de ensino da Filosofia, baseado no questionamento e na problematização, aspectos tão caros a uma postura reflexiva diante da realidade.

A Filosofia no modelo socrático, a ser ensinada, pode ser vista como um compromisso de pensar os aspectos da vida cotidiana de maneira crítica, criativa e comprometida. Nesse sentido, o caminho a ser percorrido se pauta no perguntar e no perguntar-se.

A esse respeito, Sacristán (1999, p. 99) corrobora esse método de fazer filosofia, colocando-o como uma legítima forma de filosofar.

\footnotetext{
A ação genuinamente humana, aquela que merece esse nome, é sempre reflexiva, ou seja, possui efeitos duradouros na pessoa que a realiza, e não somente no meio em que se desenvolve. Somos feitos por aquilo que fazemos, pelo modo como agimos, então, um efeito desse reflexo da ação (reflexão é o processo ou o resultado de refletir e de reflexionar) é a geração da consciência sobre a ação, que é manifestada na forma de representações, de lembranças ou de esquemas cognitivos e crenças que podem ser comunicadas, nutrindo a memória do material para pensar sobre as ações passadas e presentes e para orientar outras futuras.
}

Sócrates, que havia tomado como norte a máxima de que "[...] a vida sem exame não é vida digna de um ser humano (1996, p. 46)", tinha como caminho a busca do saber através do processo reflexivo. Somente se interrogando e interrogando as coisas e aos outros é que se poderia distanciar-se de meras opiniões sem fundamento seguro, pautadas tão somente numa espécie de comodidade que o pensamento cotidiano mostra por já estar pensado.

Sócrates, que gostava de frequentar as praças públicas de Athenas, preocupava- 
se com esse pensamento cotidiano pelo fato de ele estar impregnado de preconceitos e carente, justamente, de uma análise mais criteriosa que tornasse o homem mais digno da denominação de ser racional. Dessa maneira, pode-se dizer que: "Seu papel não era promover uma teoria, ainda menos destruir, mas estimular. Fazia o seu dever de cidadão, opunha-se às ordens iníquas, mas não procurava impor-se no campo político. Estava ali para instigar" (JEANNIÈRE, 1995, p. 14).

Foi justamente por isso, por insistir que devemos analisar com cuidado as nossas crenças, por defender essa forma de apropriar-se da filosofia, que Sócrates foi acusado de estar corrompendo a juventude, como o próprio Sócrates acusa:

[...] os moços que espontaneamente me acompanham - e são os que dispõem de mais tempo, os das famílias mais ricas - sentem prazer em ouvir o exame dos homens; eles próprios imitam-me muitas vezes; nessas ocasiões, metemse a interrogar os outros; suponho que descobrem uma multidão de pessoas que supõem saber alguma coisa, mas pouco sabem, quiçá nada. Em conseqüência, os que eles examinam se exasperam contra mim e não contra si mesmos, e propalam que existe um tal Sócrates, um grande miserável, que corrompe a mocidade (1996, p. 34).

Como se pode constatar, Sócrates, já naquela época, estava preocupado com um tipo de pensamento cotidiano, destituído de crítica. Ele não só se preocupava com o fato de que as pessoas, na sua grande maioria, não se ocupavam de revisar as suas crenças, como se achava a serviço de uma divindade quando mostrava ao seu interlocutor que ele ignorava a maior parte das coisas que se dizia conhecedor.

\section{Sócrates e o ensino de Filosofia: a abertura para o diálogo como primeiro passo}

Sócrates pensava no questionamento como um profícuo método para fazer o indivíduo refletir sobre o cotidiano e o conjunto de crenças que se formam ao seu redor. Nesse caso, trata-se mesmo de levar a dúvida às suas últimas consequências.

\footnotetext{
Colocar tudo à prova é uma das características fundamentais do conhecimento filosófico. Tal exigência nos parece ser um dos problemas estruturais de ensino de filosofia. Como ensinar, colocando tudo à prova? É justamente neste ponto que reside uma das grandes contribuições de Sócrates à docência de filosofia (SOFISTE, 2007, p. 62).
}

Para Sócrates, as crenças deveriam estar comprometidas com o pensamento rigoroso e crítico, sendo que a dúvida é que abriria a porta de acesso a esse conhecimento mais seguro. Duvidar de tudo, não por leviandade, mas para se avaliarem 
com segurança as bases nas quais as crenças estão assentadas. Todos têm o próprio conjunto básico de crenças. Seria até mesmo impossível alguém viver, na prática, sem abraçar um conjunto de crenças com as quais pudesse orientar a sua vida. As crenças são como uma espécie de bússola, ou para se colocar as coisas em um contexto mais moderno num tipo de GPS, pois fornecem coordenadas para que não se aja na mais completa desorientação e incerteza. Pensa-se ser oportuno o método de Sócrates de colocar em dúvida as principais crenças correntes, uma vez que permite maior depuração das mesmas, permitindo uma maior confiança nas que resistirem ao bombardeio da investigação.

É muito importante, nesse momento, dizer que incentivar a reflexão nos alunos, bem ao gosto de Sócrates junto aos seus discípulos, significa que é preciso que se crie um clima propício a essa atitude. Nenhuma pessoa sensata se exporá através da menção de seus pensamentos, a menos que sinta uma mínima segurança em fazê-lo. É que, enquanto se está calado, torna-se impossível saber se aquela pessoa está pensando uma tolice ou não. O que se quer pontuar com isso é que precisa existir uma atmosfera que deixe à vontade quem quer que esteja com vontade de falar. É necessário que essa pessoa não se sinta inibida, ou constrangida a não se pronunciar a respeito do que lhe vem à cabeça.

Nesse sentido, existem alguns cuidados que todo professor ou qualquer pessoa que se disponha a coordenar um diálogo tenha que observar. É que nem todos se sentem estimulados a emitir a sua opinião, mesmo que convidados a isso; é preciso que se sintam bem à vontade para tanto. O professor precisa estar atento a esse fato e buscar elementos metodológicos que favoreçam o diálogo.

Colocar em ação o método do diálogo socrático exige um professor sensível a esses pormenores, uma vez que, a princípio, podem ser fáceis de serem observados, mas, no cotidiano, exigem um esforço concentrado, tanto por parte do professor, como da parte dos alunos, para que essas aprendizagens se deem de forma efetiva. Não se pode esquecer que em todo diálogo existe uma tensão. Quem fala gosta de estar certo no que está falando. Raríssimas vezes (e isso também exige um aprendizado) não se fica com certo aborrecimento (embora alguns consigam disfarçar muito bem) quando se é contestado em seus argumentos. O próprio Sócrates deixou muita gente com uma má disposição para com ele por causa de, através do seu método, destruir os argumentos do seu interlocutor. Portanto precisa-se estar cônscio de que, pela própria natureza do diálogo, normalmente surgirão momentos de tensão que precisam ser contornados para 
que o mais importante seja a busca de verdade e não o ganhar a discussão em si mesma. Sem falar que é preciso ter cuidado para que essa fonte de construção de conhecimento, o diálogo, não sirva para criar desafetos entre as pessoas. Precisa-se aceitar a natureza intrínseca de um debate e se preparar da melhor maneira para ele.

\begin{abstract}
Considerando que o prefixo dia indica divisão e separação (através de) e logoi (discurso, fala), o diálogo supõe a presença de um entre coisificador e diversificador. Do ponto de vista epistemológico é a pergunta que irá possibilitar a abertura deste espaço do entre. Portanto, considerar o diálogo como princípio pedagógico significa superar a lógica da afirmação, visto que a pergunta rompe as medidas da validade. Um fazer educativo que se fundamenta em tais princípios pressupõe a investigação como condição fundamental, uma vez que, nesta lógica da pergunta, em cada afirmação subjaz um momento de questionabilidade (SOFISTE, 2007, p. 96-97).
\end{abstract}

Assim, vendo no diálogo uma possibilidade ímpar para se educar, o professor deve se preparar e preparar a sua turma para esse espaço do entre. Quer-se dizer que o próprio diálogo ajudará nessa tarefa. Só se vai aprender a dialogar com outras pessoas exercitando a prática do diálogo. É preciso que esse legítimo método de se fazer filosofia seja mais bem trabalhado nas aulas para que o aluno vá aprendendo a lidar com o espaço do entre (entre dois discursos), da diversidade de opiniões. Ele precisa compreender que é justamente esse espaço do entre que possibilita o avanço no conhecimento, pois é o fator que permite que a investigação siga o seu curso, coisa que não aconteceria se não existisse mais nenhuma dúvida sobre o que quer que fosse. Pontos pacíficos não exigem mais que se lhes questione, que se lhes interroguem mais, uma vez que já foram "elucidados". É de suma importância que se aprenda a conviver com o espaço do entre, que fatalmente se abrirá em um diálogo, pois é da sua ocorrência que se alimentará toda a investigação.

Respeitar o espaço do entre pode ser entendido como uma construção pautada em um saber ouvir ao outro, desenvolver a tolerância, entendendo que ninguém é o fiduciário da verdade. Ela é mesmo um processo que não se deixa capturar tão facilmente (se é que se deixa capturar).

Sobre a importância de saber ouvir para poder participar ativamente de um diálogo, traz-se agora uma importante contribuição. Nesse sentido, importante se torna agora transcrever essa passagem, em que se crê que Kohan (2000, p. 108) foi bastante feliz em sua reflexão:

Consideramos, por exemplo, a prática de escutar atentamente aos outros 
membros da comunidade. Isto é condição do diálogo filosófico: não há diálogo se os participantes não se escutam com atenção. Ao mesmo tempo, ela cultiva a auto-estima naqueles que se sentem reconhecidos pelos seus pares como portadores de uma linguagem significativa, e promove a reciprocidade e a cooperação quando quem escuta atentamente tem a sua vez de falar. Por último, isto leva a pessoa a reconhecer-se nas palavras dos demais e a estes na próxima vez. Esta prática - e todas as outras promovidas numa comunidade de questionamento e investigação - tentam criar um contexto social de modo que as pessoas a ele expostas internalizem essas práticas e possam depois recriá-los em todos os âmbitos da sua experiência.

Concorda-se com a citação acima, sobretudo no que tange à possibilidade de se reconhecer nas palavras dos outros quando se lhes dá a oportunidade de falarem. É muito mais interessante quando a voz de alguém encontra eco em outras pessoas do que quando ela se perde no vazio. Por isso, além de ser de suma importância na construção do diálogo, saber ouvir ainda proporciona a possibilidade de se ser reconhecido como alguém que tem algo importante a falar, fomentando assim o espírito de pertencer a uma comunidade.

Nesse sentido, a experiência não cansa de mostrar quão desagradável se mostra alguém que não respeita a opinião dos outros; quando não sabe ouvir o que os outros membros do grupo têm a dizer, ou simplesmente aquele que, por vaidade, adora monopolizar a fala, não dando espaço para mais ninguém dela fazer uso. Pensa-se que pessoas assim precisam experienciar mais o ouvir; é uma questão mesma de aprendizado, para que assim possam ser mais úteis na construção de uma comunidade investigativa. O professor precisa estar muito atento a esses pormenores quando se quiser valer do princípio pedagógico do diálogo socrático.

\section{A preocupação ética: Sócrates como divisor de águas na investigação da conduta humana}

Prosseguindo, faz-se necessário colocar um elemento novo nesse argumento. É que levar uma vida reflexiva, de análise, pautada no diálogo, requer, na visão de muitos pensadores, uma vida pautada no compromisso ético. Entre eles, Freire (1999, p. 37) é bastante enfático e irredutível quando toca nesse ponto:

Não é possível pensar os seres humanos longe, sequer, da ética, quanto mais fora dela. Estar longe, ou pior, fora da ética, entre nós, mulheres e homens, é uma transgressão. É por isso que transformar a experiência educativa em puro treinamento técnico é amesquinhar o que há de fundamentalmente humano no exercício educativo: o seu caráter formador. 
Não basta só que o professor diga aos seus alunos que eles precisam refletir acerca das suas crenças; que eles precisam saber ouvir aos outros, respeitar o ponto de vista do outro; que precisam defender os seus argumentos tendo cuidado em não hostilizar ao outro; mas torna-se imperioso que ele mesmo tenha uma conduta condizente com o seu discurso. O dito tem de caminhar junto com o feito. Isso é mesmo uma questão de probidade do sujeito que se utiliza de um determinado discurso.

\begin{abstract}
O professor que realmente ensina, quer dizer, que trabalha os conteúdos no quadro da rigorosidade do pensar certo, nega, como falsa, a fórmula farisaica do "faça o que mando e não o que eu faço". Quem pensa certo está cansado de saber que as palavras a que falta a corporeidade do exemplo pouco ou quase nada valem. Pensar certo é fazer certo (FREIRE, 1999, p. 38).
\end{abstract}

Sempre insisti, mesmo na época da Graduação, de que a Filosofia, seja qual for o seu campo de atuação, sempre vai culminar em uma ética. Sempre se estará às voltas com decisões a serem tomadas que exigirão uma justificativa sobre o porquê de ser assim e não de outra forma. Toda justificativa para as ações pode simplesmente esbarrar no muro da improbidade daquele que prega algum discurso e não o pratica efetivamente. É preciso ao menos buscar um esforço para viver de acordo com o que se prega como a coisa certa.

Nesses termos, a questão ética parece coroar todo o aspecto da vida prática. Até mesmo a questão socrática por excelência que mostra que a vida não analisada não é digna de ser vivida provoca questão: e que tipo de vida é digna de ser vivida? Obviamente, a resposta não nasce com a pessoa, precisa ser buscada.

Ora o valor de uma vida, o que é necessário para que ela seja digna de ser vivida, não nos é dado de início, ab ovo, com nosso nascimento: ele deve ser obtido, construído, conquistado, ele reclama um trabalho de si sobre si mesmo, uma elaboração, uma transformação de si. É esse cuidado de si, a cura sui dos latinos com vistas a uma vida que valha a pena, que merece rigorosamente o nome de ética (PRADO JR., 2008, p. 61-62).

Retomando o fio da meada, poder-se-ia acrescentar que, se alguém tivesse um indício de qual tipo de vida deveria ser digna de ser vivida, então, por que não viveria em conformidade com ela? 
Talvez fosse por isso que Sócrates tanto quis pautar a sua vida em conformidade com a sua filosofia, pois é muito mais convincente um discurso que se sustenta na prática do que um vazio, montado apenas em palavras soltas ao vento. É como diz o ditado: a palavra convence, mas o exemplo arrasta ${ }^{5}$.

A questão da educação reflexiva deve justamente culminar em uma ética que exija a justificação do tipo de vida que se quer adotar. Não é por acaso que Sócrates é um divisor de águas na Filosofia. É a partir dele que há um deslocamento do eixo da filosofia das questões cosmológica às éticas. A partir dele, tem início o período antropológico ou socrático da Filosofia. De acordo com Chauí (2004, p. 41), o período antropológico ou socrático é assim chamado pela importância que Sócrates exerceu no pensamento da sua época. "Propunha que, antes de querer conhecer a natureza e antes de querer persuadir os outros, cada um deveria, primeiro e antes de tudo, conhecer-se a si mesmo [...]”. E mais adiante, a autora finaliza:

Por fazer do autoconhecimento ou do conhecimento que os homens têm de si mesmos a condição de todos os outros conhecimentos verdadeiros é que se diz que o período socrático é antropológico, isto é, voltado para o conhecimento do homem (em grego, ántropos), particularmente de seu espírito e de sua capacidade para conhecer a verdade (CHAUÍ, 2004, p. 41).

Outro autor que dá subsídios a esta discussão é Pinheiro (2004) que, mesmo tratando da conversão filosófica em Platão, ${ }^{6}$ propicia uma boa análise acerca da importância da coerência entre os enunciados filosóficos e a ética com a qual se deve pautar a existência.

Para Pinheiro, existe uma estreita ligação entre ética e teoria do conhecimento, pois existe uma implicação ética presente em todo conhecimento filosófico rigoroso. Por isso a necessidade que se faz presente em harmonizar a vida com as próprias afirmações. Nesse sentido, uma vida pautada na coerência entre o que se diz e o que se realiza objetivamente faz parte do cuidado de si mesmo de todos aqueles que se lançam na filosofia.

\footnotetext{
5 "Verba movent, exempla trahunt".

6 Não podemos nos esquecer da importante influência de Sócrates no pensamento de Platão. O último via no primeiro um modelo de homem justo e coerente. Sem falar no fato de que Sócrates nada escreveu, sendo nos diálogos platônicos, nos relatos do general Xenofonte, nas sátiras de Aristófanes e nos escritos posteriores de Aristóteles, que podemos travar contato com o pensamento e a vida de Sócrates (Cf. GOTTLIEB, 1999, p. 24).
} 
Com efeito, ele menciona que é justamente essa busca de coerência entre as afirmações proposicionais e a vida do interlocutor que faz parte da estratégia de Sócrates para flagrar o seu interlocutor em contradição. A própria palavra contradição (contradicção: contradizer a fala) remete a algo que é dito, mas que é contradito por algum motivo. Nesse caso, a contradição diz respeito à incompatibilidade entre o discurso e a prática.

Nesse sentido, Pinheiro corrobora o pensamento de que não deve haver separação entre a vida ética de cada pessoa e a investigação filosófica, na qual se pretenda enveredar. Ou seja, as elucubrações filosóficas devem, ou pelo menos deveriam, caminhar pari passu com as resoluções existenciais de cada pessoa.

Em outro texto, mas com a mesma concepção defendida, Pinheiro (2005) chama a atenção para o fato de que os textos antigos, além de trazerem um importante material na forma de belos sistemas filosóficos, são muito profícuos no que tange a uma busca por uma experiência vital.

[...] podemos salientar que esta expressão chama atenção para o fato de a filosofia antiga não se dar apenas no âmbito racional, mas que - mesmo sendo, sem dúvida, um exercício racional - alcança a totalidade da alma humana. É necessária uma entrega total da alma na investigação filosófica para que ela se dê de modo rigoroso, isto é, para que ela alcance o seu objetivo supremo, a transformação da vida em uma vida boa (PINHEIRO, 2005, p.174).

Sendo assim, não é apenas o âmbito do racional que deve ser vislumbrado com a prática da filosofia, mas a questão ética também é de suma importância caso se queira contemplar "a totalidade da alma humana", justamente na sua dimensão mais humana, que é a existência ética.

Assim sendo, o exercício da filosofia não é apenas um aprimoramento do intelecto para que seja utilizado em discussões acaloradas, sem nenhuma contribuição efetiva à vida, mas uma experiência vital, algo que transforme efetivamente a vida daqueles que pratiquem a experiência do filosofar, não só em bases racionalistas discursivas, mas, acima de tudo, que toque com força nas questões existenciais mais delicadas com as quais se convive.

É interessante notar que a experiência vital reivindicada pelos filósofos da antiguidade encontre eco em nossos dias, principalmente quando se veem educadores como Paulo Freire, para quem tal experiência seria tanto mais significativa, quanto 
estivesse permeada de curiosidade, enquanto inquietação indagadora pela busca do esclarecimento.

Como manifestação presente à experiência vital, a curiosidade humana vem sendo histórica e socialmente construída e reconstruída. Precisamente porque a promoção da ingenuidade para a criticidade não se dá automaticamente, uma das tarefas precípuas da prática educativo-progressista é exatamente o desenvolvimento da curiosidade crítica, insatisfeita, indócil (FREIRE, 1999, p. 35-36).

Justamente, para que essa curiosidade pudesse avançar criticamente e transformar-se em uma curiosidade epistemológica, seria preciso um compromisso ético para que fossem evitadas transgressões de uma conduta moralmente correta e responsável. "É no domínio da decisão, da avaliação, da liberdade, da ruptura, da opção, que se instaura a necessidade da ética e se impõe a responsabilidade. A ética se torna inevitável e sua transgressão possível um desvalor, jamais uma virtude" (FREIRE, 1999, p. 20). Novamente, a questão da ética como ponto culminante das ações humanas se impõe.

\section{Considerações finais}

Se a vida não analisada não é digna de ser vivida, muito menos é digna sem ser digna. O jogo de palavras não deixa de evidenciar a importância do conhecimento atrelado a ética, do bem pensar com o bem agir.

Nunca é demais dizer que, em se tratando de uma totalidade da alma, as questões do cotidiano servem, sim, de referência. A filosofia é um processo que enseja a análise de assuntos do cotidiano e a forma como abordá-las. Nesse sentido, a reflexão filosófica funciona como uma forma de depuração, muitas vezes dolorosa, das teorias de mundo erigidas no dia-a-dia e no âmago das relações sociais.

Por isso, a procura por caminhos que favoreçam ao pensamento deve ser incentivada. No caso das aulas de Filosofia, muitas são as possibilidades de estimular o aluno no processo da reflexão e da criticidade.

Além disso, o professor precisa enfatizar a importância da corporeidade do exemplo, o compromisso do pensamento com as ações. De pouco adianta, do ponto de vista ético, um aluno hábil com as palavras, mas que fale sem veracidade; eloquente no discurso, mas vazio na probidade; estamos cheios desse tipo de gente e não precisamos 
reforçar esse comportamento em sala de aula. O professor precisa, ele mesmo, ter um comportamento que ateste o seu discurso.

Sócrates, através de sua vida, de seus exemplos e da maneira como concebia o exercício do filosofar pode ser bem empregado, tanto como conteúdo, como também na maneira didática como ele mediava a Filosofia. Precisamos reabilitar melhor o patrono da Filosofia, "o velho mutuca", em nossas salas de aulas, sobretudo com esses jovens carentes de exemplos inspiradores.

\section{REFERÊNCIAS}

AIRES, Maurilio G. $O$ ensino de filosofia no ensino médio mediado pela literatura sartriana. 2010. 259f. Tese (Doutorado em Educação) - Centro de Ciências Sociais Aplicadas, Universidade Federal do Rio Grande do Norte, Natal.

CHAUÍ, Marilena. Convite à filosofia. 13. ed. São Paulo: Editora Ática, 2004.

FREIRE, Paulo. Pedagogia da autonomia: saberes necessários à prática educativa. 11 . ed. São Paulo: Paz e Terra, 1999. (Coleção leitura)

GOTTLIEB, Anthony. Sócrates: o mártir da filosofia. Tradução de Irley Fernandes Franco. São Paulo: UNESP, 1999. (Coleção grandes filósofos)

JEANNIÉRE, Abel. Platão. Tradução de Lucy Magalhães. Rio de Janeiro: Zahar, 1995. (Biblioteca de filosofia)

KOHAN, Walter O. Fundamentos para compreender e pensar a tentativa de Matthew Lipman. In: KOHAN,Walter; WENSCH, Ana Míriam (orgs.). Filosofia para crianças: a tentativa pioneira de Matthew Lipman. 3. ed. Petrópolis: Vozes, 2000. (Série Filosofia na Escola)

PINHEIRO, Marcus R. Conversão filosófica, dialética e educação na república de Platão. Rio de Janeiro: Análogos/PUCRJ, v. 4, 2004, p. 205-217.

Filosofia, saúde, alma e corpo no Cármides de Platão. Natal: Princípios/UFRN, v. 12, n. 17-18, jan./dez. 2005, p. 173-182.

PLATÃO. Defesa de Sócrates. Tradução de Jaime Bruna. Seleção de textos de José Américo Motta Pessanha. São Paulo: Nova Cultural, 1996. (Coleção os pensadores)

PRADO JR. Plínio W. Aprender a viver - Wittgenstein e o "não-curso" de filosofia. In: BORBA, Siomara; KOHAN, Walter (orgs.). Filosofia, aprendizagem, experiência. Belo Horizonte: Autêntica Editora, 2008.

SACRISTÁN, J. Gimeno. Poderes instáveis em educação. Tradução de Beatriz Affonso Neves. Porto Alegre: Artes Médicas, 1999. 
REVISTA DO NESEF FILOSOFIA E ENSINO. CURITIBA. ISSN 2317-1332

SOFISTE, Juarez Gomes. Sócrates e o ensino da filosofia: investigação dialógica: uma pedagogia para a docência de filosofia. Petrópolis: Vozes, 2007. 